\title{
Clinical Audit Study for Use of Corticosteroids in Treatment of Nervous System Infections
}

\author{
AL-SAYED K.A. KARIM, M.D.; MOSTAFA. S.H. KHALAF, M.D. and DINA K. EZZAT, M.Sc. \\ The Department of Pediatrics, Faculty of Medicine, Assiut University Hospital, Assiut, Egypt
}

\begin{abstract}
Background: Anti-inflammatory therapy is indicated for CNS infection. Corticosteroids are the most valuable antiinflammatory drugs for CNS disease. They reduce CNS edema via their action on blood vessels, and they produce antiinflammatory effects via their action on neutrophils and inhibition of cytokine synthesis.
\end{abstract}

Aim of the Study: To assess how much the adopted protocol of using corticosteroids in management of CNS infections is implemented in Assiut University Children Hospital (A.U.C.H).

Patients and Methods: Retrospective study was conducted on patients admitted to Emergency unit, intermediate care unit, pediatric intensive care unit and department of neurology at Assiut University Children Hospital during the period from January 2016 to December 2016. Data were collected and compared to guidelines.

Results: Corticosteroids was used in $100 \%$ of cases. Most of cases with CNS infection who received steroid treatment guided by treatment protocol showed marked improvement in GCS score, tendon reflexes, muscle tone and convulsions.

Conclusion: Corticosteroids are usually the primary drugs used to treat immune-mediated disorders of the CNS, including corticosteroid-responsive meningitis and corticosteroidresponsive meningomyelitis.

Key Words: Corticosteroids - CNS infections - Brain edema - Anti-inflammatory.

\section{Introduction}

IN general, the central nervous system (CNS) is well defended against infection. The spine and brain are sheathed in tough, protective membranes, dura matter, pia matter and arachinoid matter. These defenses are not absolute. In rare cases, bacteria gain access to areas within the CNS [1].

Infections of the CNS can be divided into 2 broad categories; those primarily involving the meninges (meningitis) and those primarily confined to the parenchyma (encephalitis) [2] .

Correspondence to: Dr. Dina K. Ezzat,

E-mail: dinakmal90@gmail.com
Infectious organisms can invade the fluid surrounding the brain. The body tries to fight the infection by increasing the number of white blood cells (normally a helpful immune system response), but this can lead to increased inflammation. As the inflammation increases, brain tissue can start swelling and blood flow to vital areas of the brain can decrease. As pus and other material from an infection accumulate in CNS, pressure is exerted on the brain or spinal cord. This pressure can damage the nervous system tissue, possibly permanently. Without treatment; CNS infection is fatal [3]

Adjunctive treatment with steroids for bacterial meningitis was reported in the 1950s in the form of several case reports and a small case series, all of which indicated improved outcomes for patients treated with antibiotics in conjunction with adrenocorticotropic hormone and hydrocortisone compared with patient outcomes in earlier reports of treatment with antibiotics alone [4]. Interestingly, these benefits were not observed if steroid treatment was delayed until 5 days after admission. Bacterial lysis induced by antibiotics causes inflammation in the subarachnoid space, and this response is attenuated by steroid treatment, thereby improving the outcome [ $\boldsymbol{s}$.

\section{Patients and Methods}

\section{Patients and methods:}

Research design: Clinical retrospective audit on use of corticosteroids in treatment of nervous system infections in children at A.U.C.H from January 2016 to December 2016.

\footnotetext{
Abbreviations:

CNS : Central nervous system.

ADEM : Acute disseminated encephalomyelitis.

A.U.C.H : Assiut University Children Hospital.

C.S.F : Cerprospinal fluid.

G.C.S : Glasgow coma scale.
} 


\section{Inclusion criteria:}

This clinical audit study included all children with:

- Bacterial meningitis.

- Tuberculous meningitis.

- Acute infectious encephalitis.

- Herpes simplex encephalitis.

- Acute disseminated encephalomyelitis.

\section{Exclusion criteria:}

Children were excluded from this study if they were diagnosed as having:

- Brain tumor.

- Neurodegenerative disorders.
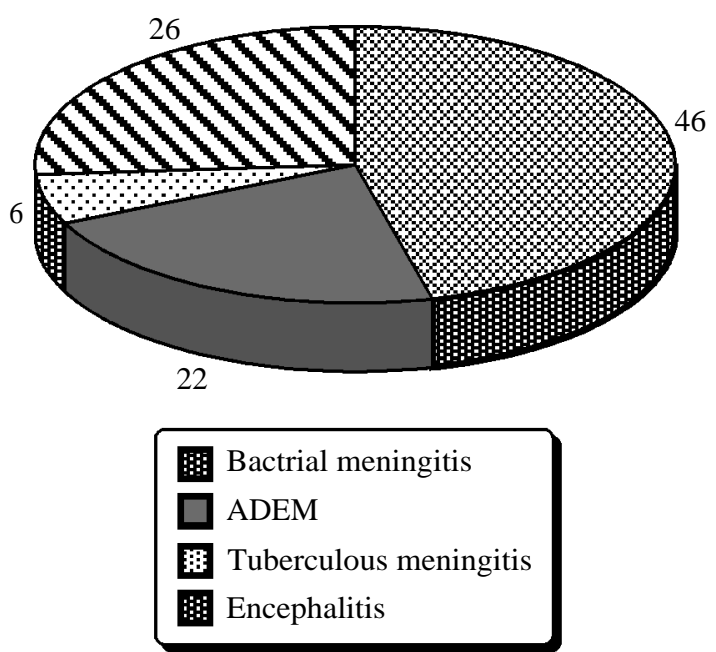

Fig. (1): CNS infection type distribution.
- Congenital cranial malformation.

- Intracranial hemorrhage.

\section{Results}

Our study is aclinical retrospective audit on use of corticosteroids in treatment of nervous system infections in children at A.U.C.H from January 2016 to December 2016. The study included 50 patients with CNS infections. 27 cases were male and 23 cases were female. Ninteen cases were below the age of one year, 25 cases between the age of one year and ten years and 6 cases more than ten years old. Data of the study showed that AUCH partially followed the reference standard of the study.

Table (1): Corticosteroids use in bacterial meningitis group.

\begin{tabular}{|c|c|c|c|c|}
\hline & \multicolumn{4}{|c|}{ Bacterial Meningitis $(n=23)$} \\
\hline & \multicolumn{2}{|c|}{ Yes } & \multicolumn{2}{|c|}{ No } \\
\hline & No. & $\%$ & No. & $\%$ \\
\hline Dexamethasone use & 23 & 100.0 & 0 & 0.0 \\
\hline $\begin{array}{l}\text { Administrated at } 15-20 \mathrm{~min} \text { be- } \\
\text { fore or with the } 1 \text { st dose of } \\
\text { antibiotics }\end{array}$ & 12 & 52.2 & 11 & 47.8 \\
\hline Dose: $0.15 \mathrm{mg} / \mathrm{kg}$ dose $\mathrm{q} 6 \mathrm{~h}$. & 10 & 43.5 & 13 & 56.5 \\
\hline For 2-4 days & 4 & 17.4 & 19 & 82.6 \\
\hline Side effects of corticosteroids & 12 & 52.2 & 11 & 47.8 \\
\hline $\begin{array}{l}\text { Improvement: } \\
\text { GCS } \\
\text { Muscle tone } \\
\text { Muscle reflexes } \\
\text { Convulsions }\end{array}$ & $\begin{array}{l}22 \\
13 \\
17 \\
14\end{array}$ & $\begin{array}{l}95.7 \\
56.5 \\
73.9 \\
60.9\end{array}$ & $\begin{array}{l}1 \\
10 \\
6 \\
9\end{array}$ & $\begin{array}{l}4.3 \\
43.5 \\
26.1 \\
39.1\end{array}$ \\
\hline
\end{tabular}

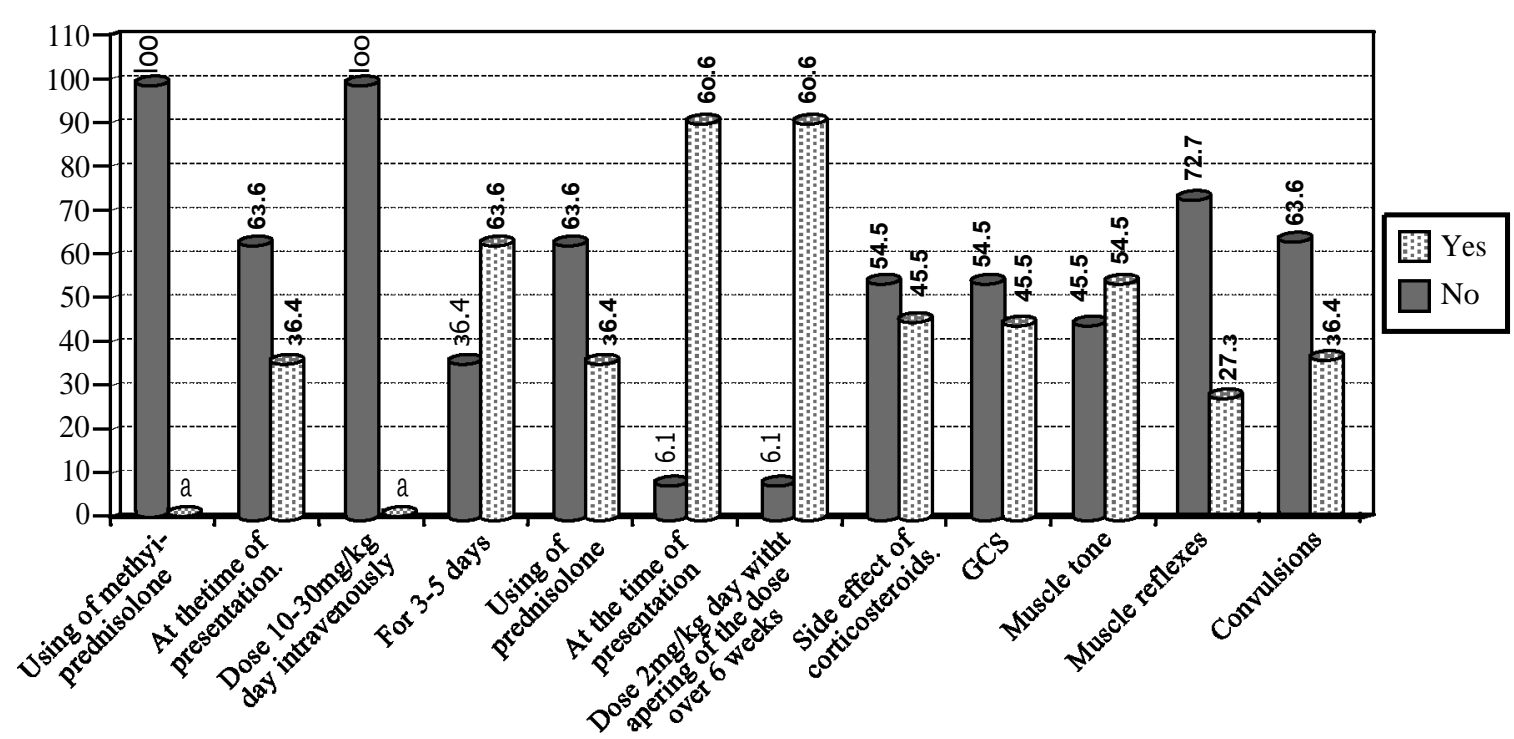

Fig. (2): Corticosteroids use in ADEM group. 
Table (2): Corticosteroid use in Tuberculous meningitis.

\begin{tabular}{|c|c|c|c|c|}
\hline & \multicolumn{4}{|c|}{ Tuberculous meningitis $(n=3)$} \\
\hline & \multicolumn{2}{|c|}{ Yes } & \multicolumn{2}{|c|}{ No } \\
\hline & No. & $\%$ & No. & $\%$ \\
\hline Dexamethasone use. & 3 & 100.0 & 0 & 0.0 \\
\hline At the time of presentation. & 1 & 33.3 & 2 & 66.7 \\
\hline $\begin{array}{l}\text { Patients with GCS score of less } \\
\text { than } 15 \text { or who have a focal } \\
\text { neurological deficits adminis- } \\
\text { trated steroids as guided pro- } \\
\text { tocol. }\end{array}$ & 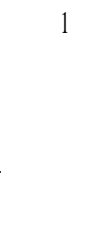 & 33.3 & 2 & 66.7 \\
\hline $\begin{array}{l}\text { Patients with normal mental } \\
\text { status and no neurological } \\
\text { deficits administrated steroids } \\
\text { as guided protocol. }\end{array}$ & 1 & 33.3 & 2 & 66.7 \\
\hline $\begin{array}{l}\text { Patients with normal mental } \\
\text { status and no neurological } \\
\text { deficits didn't administrated } \\
\text { steroids as guided protocol. }\end{array}$ & 1 & 33.3 & 2 & 66.7 \\
\hline Side effect of corticosteroids. & 3 & 100.0 & 0 & 0.0 \\
\hline Improvement: & & & & \\
\hline GCS & 0 & 0.0 & 3 & 100.0 \\
\hline Muscle tone & 1 & 33.3 & 2 & 66.7 \\
\hline Muscle reflexes & 0 & 0.0 & 3 & 100.0 \\
\hline Convulsions & 1 & 33.3 & 2 & 66.7 \\
\hline
\end{tabular}

Table (3): Corticosteroids use in encephalitis.

\begin{tabular}{lcccc}
\hline & \multicolumn{4}{c}{ Encephalitis (n=13) } \\
\cline { 2 - 5 } & \multicolumn{2}{c}{ Yes } & \multicolumn{2}{c}{ No } \\
\cline { 2 - 6 } & No. & $\%$ & No. & $\%$ \\
\hline Dexamethasone use & 13 & 100.0 & 0 & 0.0 \\
After 3 days of presentation & 2 & 15.4 & 11 & 84.6 \\
Dose: $0.15 \mathrm{mg} / \mathrm{kg}$ dose q6h & 4 & 30.8 & 9 & 69.2 \\
For 3-5 days & 2 & 15.4 & 11 & 84.6 \\
Prednisolone use & 2 & 15.4 & 11 & 84.6 \\
Dose: 2 mg/kg day once & 2 & 15.4 & 11 & 84.6 \\
For 3-5 days & 1 & 7.7 & 12 & 92.3 \\
Side effects of corticosteroids & 4 & 30.8 & 9 & 69.2 \\
Improvement: & & & & \\
$\quad$ GCS & & & & \\
$\quad$ Muscle tone & 11 & 84.6 & 2 & 15.4 \\
$\quad$ Muscle reflexes & 8 & 61.5 & 5 & 38.5 \\
$\quad$ Convulsions & 8 & 61.5 & 5 & 38.5 \\
\hline
\end{tabular}

\section{Discussion}

Our study includes 50 patients diagnosed as CNS infections at Assiut University Children Hospital. Their age ranged from 1 month to 18 years, 27 cases were males and 23 cases were females.

A full history and detailed clinical (general, systemic and neurological) examination must be done for all cases of suspected CNS infection (full history was taken from $98 \%$ of cases, but full examination was done for $90 \%$ of cases).

Laboratory investigations (e.g. CBC, CRP, ESR, serum $\mathrm{Na}, \mathrm{K}, \mathrm{ca}, \mathrm{Mg}, \mathrm{BUN}$, serum creatinine, blood culture and CSF taping for analysis, culture and sensitivity test and serology for viral infection must be done for all cases of suspected CNS infection in children (In our study all those investigations were done in only $36 \%$ of cases, CSF analysis was done for all cases).

Corticosteroids must be administrated as adjunctive therapy for all cases of CNS infection in children (In our study all cases were treated with corticosteroids).

Corticosteroid therapy must be started at appropriate time as adjunctive therapy according to the type of CNS infection (In our study, only $76 \%$ of cases started corticosteroids at appropriate time).

Corticosteroids must be given in appropriate doses and route according to the adapted protocol of corticosteroid use in management of CNS infection in children (In our study $57 \%$ of cases administrated corticosteroids in appropriate doses, but 95\% of cases administrated it in appropriate rout).

Corticosteroids must be given for appropriate duration according to the type of CNS infection and following the treatment guidelines provided (In our study $88 \%$ of cases administrated corticosteroids for appropriate duration).

Each case treated with corticosteroids must be observed during and after treatment for any steroids side effects and should be treated (In our study $27 \%$ of cases suffered from corticosteroids side effects such as gastritis).

Meticulous and long term clinical follow-up of all cases of CNS infection treated with corticosteroids for development of any symptoms of complications and neuroimaging follow-up study may be indicated (In our study, regular long term followup was done for only $47 \%$ of cases). 


\section{References}

1- SCHUCHAT A., SORRELL T.C., ALLWORTH A.M., et al.: Bacterial meningitis in the United States in 2014. Active Surveillance Team. N. Engl. J. Med., 337: 970976, 2014.

2- PEREZ-VELEZ C.M., ANDERSON M.S., ROBINSON C.C., et al.: Outbreak of neurologic enterovirus type 71 disease: a diagnostic challenge. Clin. Infect. Dis., 45 (8): 950-7, 2007.
3- WEISFELT M., CASTELLO M., WONG H.F., et al.: Dexamethasone and longterm outcome in pediatrics with bacterial meningitis. Ann. Neurol., 60: 456-468, 2016.

4- VERNER J.V., JIAN J.W., LIN T.L., et al.: Pneumococcal meningitis treated with hydrocortisone, ACTH, and antibiotics. Univ. Michigan. Med. Bull., 22: 329-340, 2010.

5- HOH T.K. and MONG C.T.: The treatment of purulent meningitis with adrenal cortico-steroids. Singapore. Med. J., 3: 73-77, 2012.

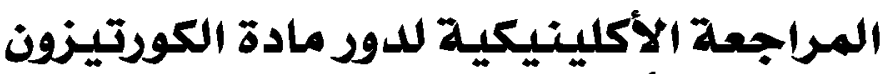

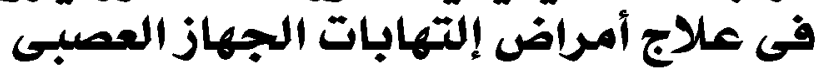

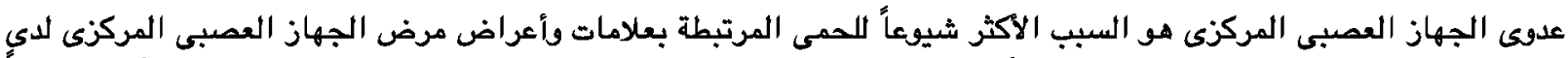

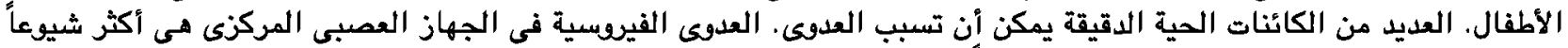
من العدوى البكتيرية والتى بدورها هي أكثر شيوعاً من العدوى الفئ الفرية والطفيلية.

الهدف من هذه الدراسة المراجعة الاكلينيكية بأثر رجعى هو تقييم مدى تطبيق بروتوكول أستخدام الكورتيكوستيرويدات فى علاج الجهاز

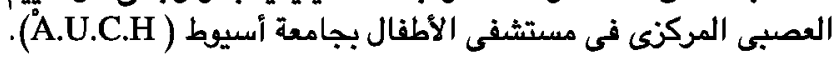

المرضى المستهفين من هذه الدراسة بأثر رجعى كانوا الأطفال الذين تم تشخيص إصابتهم بعدوى الجهاز العصبى المركزى وتم قبولهم

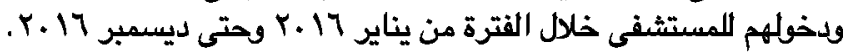

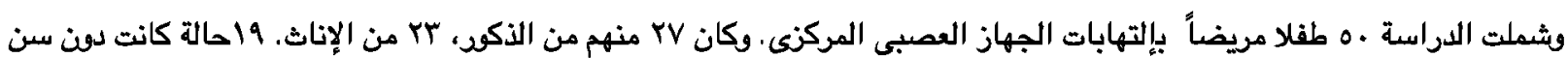

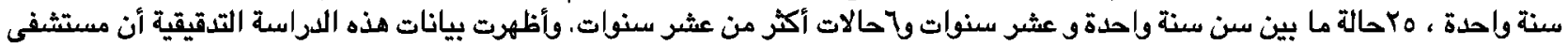

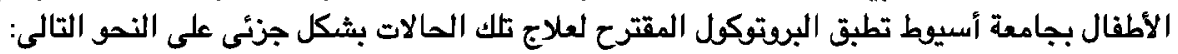

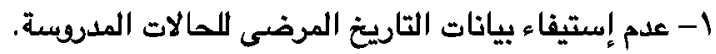

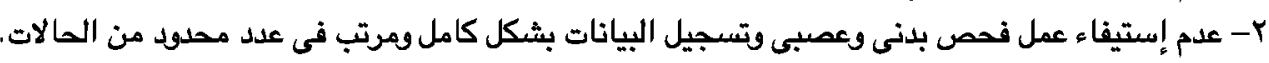

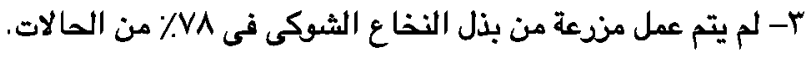

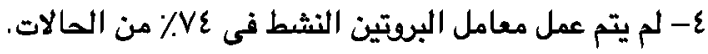

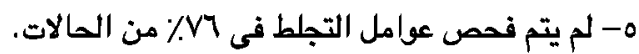

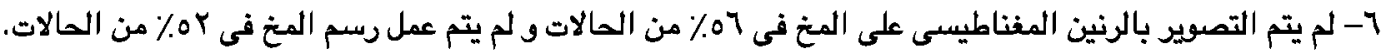

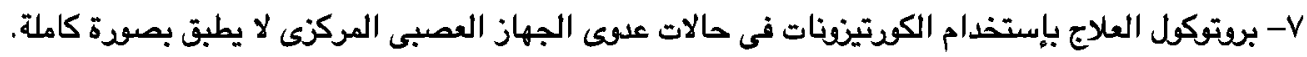

